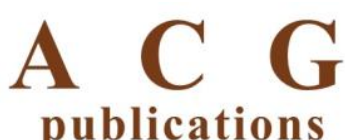

Rec. Nat. Prod. 14:1 (2020) 1-17

records of natural

products

\title{
Roselle Seed Oil and its Nano-Formulation Alleviated Oxidative Stress, Activated Nrf2 and Downregulated m-RNA Expression Genes of Pro-inflammatory Cytokines in Paracetamol-intoxicated Rat Model
}

\author{
Mai E. Hussein $\oplus^{1}$, Amira S. El Senousy ${ }^{1 *}$, Wessam H. Abd-Elsalam ${ }^{2}$, \\ Kawkab A. Ahmed $\oplus^{3}$, Hesham I. El-Askary ${ }^{\oplus}{ }^{1}$, Samar M. Mouneir $\oplus^{4}$ \\ and Ahlam M. El Fishawy 1
}

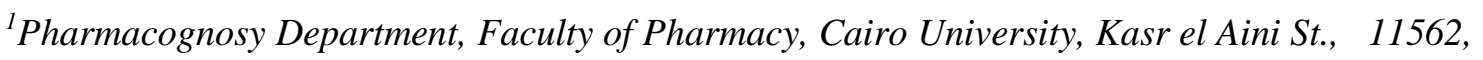 \\ Cairo, Egypt \\ ${ }^{2}$ Pharmaceutics and Industrial Pharmacy Department, Faculty of Pharmacy, Cairo University, Kasr \\ el Aini St., 11562, Cairo, Egypt \\ ${ }^{3}$ Pathology Department, Faculty of Veterinary Medicine, Cairo University, Giza Square, 12211, Giza, \\ Egypt \\ ${ }^{4}$ Pharmacology Department, Faculty of Veterinary Medicine, Cairo University, Giza Square, 12211, \\ Giza, Egypt
}

(Received March 19, 2019; Revised May 22, 2019; Accepted May 23, 2019)

\begin{abstract}
Roselle (Hibiscus sabdariffa L.) seeds, traditionally used in liver disorders, have recently attracted more attention as a new source of healthy edible oil with anti-inflammatory and antioxidant activities. However, its hepatoprotective effect has not been explored yet. In the current study, the hepatoprotective potential of roselle seed oil (RSO; 0.6, 4 and $8 \mathrm{~mL} / \mathrm{kg}$ ) and its nano-formulation (RSO-NE; 4 and $8 \mathrm{~mL} / \mathrm{kg}$ ), and their possible underlying mechanism were investigated in a paracetamol-induced hepatotoxicity rat model, compared to silymarin. RSO and RSO-NE protected the liver against paracetamol-intoxication and maintained the overall architecture of liver tissues in a dose dependent manner. Additionally, hepatic nuclear factor-erythroid 2-related factor2 (Nrf2) and glutathione (GSH) increased significantly in pre-treated groups, while malondialdehyde (MDA) decreased. Moreover, RSO and RSO-NE significantly inhibited paracetamol-induced mRNA expression of pro-inflammatory cytokines (TNF- $\alpha$ and IL-6). Chemical analysis of RSO showed fatty acids (mainly linoleic, oleic, palmitic and stearic acids), $n$-eicosane, $\beta$-sitosterol and tocopherols as the major constituents, which contributed synergistically to its protective effect. The efficacy of RSO-NE $(8 \mathrm{~mL} / \mathrm{kg})$ was superior to its corresponding unformulated oil $(0.6 \mathrm{~mL} / \mathrm{kg})$, indicating its enhanced bioavailability. These findings encourage the use of RSO in development of health promoting products such as food supplements, functional food and nutraceuticals for the prevention of liver disease.
\end{abstract}

Keywords: Hepatoprotective; Hibiscus sabdariffa; nanoemulsion; Nrf2; pro-inflammatory cytokines; tocopherols. (C) 2019 ACG Publications. All rights reserved.

\section{Introduction}

Liver is a crucial organ involved in a broad range of functions, such as detoxification of various metabolites, glycogen storage, protein synthesis and production of biochemicals necessary for

\footnotetext{
*Corresponding author: E-Mail: amira.elsenousy@pharma.cu.edu.eg
} 
digestion. Liver injury can be induced by toxic chemicals, xenobiotics, drugs, heavy metals, radiations and others [1]. Chronic liver disease and its complications, represent a major health burden, responsible for more than 2 million deaths every year [2]. Despite being a worldwide problem, liver diseases still suffer from inadequate medical management. Treatment options exhibit adverse effects and are often too costly, especially for developing countries [3]. Hence, growing attentions have been paid to the usage of herbal medicines due to their low toxicity and good therapeutic performance. For several years, herbal drugs have been used in the treatment of liver disorders [4].

Hibiscus sabdariffa L. (Malvaceae), popularly known as roselle or red sorrel in English and as karkadeh in Arabic, is widely distributed in tropical and subtropical regions around the world [5]. Its fruits, calyces, petals, flowers, leaves, seeds and roots have been used in ethnomedicine in the treatment of various ailments [6,7]. In Trinidad and Tobago, the seeds are used to clean liver and blood [8]. They are traditionally used in India, to treat dysuria, indigestion, diarrhea and inflammation when applied externally, and to enhance lactation in Nigeria [6,7]. Additionally, the seeds are used for their oil in Sudan and China, eaten roasted or ground in Africa, and fermented into a condiment in Nigeria [6,9]. Roselle is widely cultivated in Egypt, however huge quantities of the seeds are discarded as by-products, despite of its ethnomedicinal importance.

Recently, roselle seeds have attracted more attention, owing to their potential nutritional value as a source of protein, dietary fibre and edible oil [9-11]. Roselle seeds yield 15-20\% fixed oil of high oxidative stability, predominantly composed of linoleic and oleic acids, besides being rich in phytosterols and tocopherols [11-15], rendering it beneficial to human health. Furthermore, the application of roselle seed oil (RSO) in food industry was reported, where it improved the oxidative stability of mayonnaise, compared to corn oil [15]. However, little data was recently reported on the biological efficacy of RSO, including its anti-inflammatory [16,17], antioxidant [11] and hypolipdimic activities $[11,18]$. RSO might be a potential hepatoprotective based on its ethnomedicinal use in liver problems [8], as well as its reported antioxidant and anti-inflammatory properties [11,16,17]. However, its hepatoprotective effect has not been yet explored.

Despite of the declared usefulness of RSO, its poor water solubility may affect its nutritional quality and bioavailability, hence limit its application in medicine. Bioavailability is one of the major obstacles in the translation of preclinical potential to clinical application of poorly water soluble phytochemicals. The assimilation of plant derived oils into nanoemulsion systems has become an attractive trend owing to their long-term stability, high solubilization, ease of preparation and enhanced bio-accessibility $[19,20]$. Nanoemulsions are considered as biphasic dispersions of two immiscible phases; either water in oil (W/O) or oil in water $(\mathrm{O} / \mathrm{W})$ droplets stabilized by amphiphilic surfactant, with mean droplet size $<500 \mathrm{~nm}$ [21]. They are thermodynamically and kinetically stable, thus rarely show signs of coalescence and aggregation [20].

With this background, the current study was designed to explore the protective effect of RSO against paracetamol-induced hepatotoxicity in rats, and its possible mechanism of action. Additionally, RSO was incorporated into an efficient $(\mathrm{O} / \mathrm{W})$ nanoemulsion formulation, to test the hypothesis of the enhanced biological effect of the developed nanoemulsion (RSO-NE), compared to unformulated oil, as a new potential formulation in the prevention of liver disease. The hepatoprotective effects of RSO and RSO-NE were investigated in comparison to silymarin.

\section{Materials and Methods}

\subsection{Plant Material}

Seeds of Hibiscus sabdariffa L. were collected, in the mature fruiting stage, from Medicinal, Aromatic and Poisonous Plants Experimental Station, Faculty of Pharmacy, Cairo University, Giza, Egypt, in December 2015. The plant was identified by Dr. Mohammed El-Gebaly (Senior botanist and consultant at Orman Botanical Garden, Dokki, Egypt), and a voucher specimen (No. 6-3-2016) was kept in the Herbarium of Pharmacognosy Department, Faculty of Pharmacy, Cairo University.

\subsection{Drugs and Chemicals}

Reference tocopherols ( $\alpha, \gamma, \delta$-tocopherol), Tween 80 and polyethylene glycol (PEG 400) were 
acquired from Sigma Aldrich Chemical Co. (St. Louis, MO, USA). Paracetamol was obtained from Chemical Industries Development (CID) (Giza, Egypt). Silymarin was procured from VACSERA (Giza, Egypt). All other chemicals and reagents were of analytical grade.

\subsection{Chemical Characterization of RSO}

\subsubsection{Preparation of RSO}

Seeds were dried in shade and pulverized into a coarse powder. Two $\mathrm{kg}$ of dried powdered seeds were exhaustively extracted with petroleum ether by cold maceration (ten times with $2.5 \mathrm{~L}$ solvent). The oil was then filtered through filter paper Whatman no.1, and the solvent was evaporated under vacuum, at $50^{\circ} \mathrm{C}$. The obtained oil was dried over anhydrous sodium sulphate to yield $17.5 \%$ w/w of RSO.

\subsubsection{GC-MS of Fatty Acid Methyl Esters (FAME) and Unsaponifiable Matter (USM) of RSO}

One $\mathrm{g}$ of the seed oil was saponified with $20 \%$ alcoholic $\mathrm{KOH}$ for 24 hours, and the unsaponifiable and saponifiable fractions were separated. Fatty acids were methylated with diazomethane [22]. The USM as well as the FAME were subjected to GC/MS analysis, using Agilent HP 6890 series GC system, fitted with 5973 Mass Selective Detector. The apparatus was equipped with an HP-5MS column ( $30 \mathrm{~m}$ length, $0.25 \mathrm{~mm}$ i.d., $0.25 \mu \mathrm{m}$ film). The carrier gas was He, at a flow rate of $1.5 \mathrm{~mL} / \mathrm{min}$. The sample $(1 \mu \mathrm{L})$ was injected at a split ratio of $25: 1$. The injector and detector temperatures were $250^{\circ} \mathrm{C}$ and $280^{\circ} \mathrm{C}$, respectively. For FAME analysis, the oven initial temperature was held at $50^{\circ} \mathrm{C}$ for $1 \mathrm{~min}$, then increased to $150^{\circ} \mathrm{C}$ at a rate of $25^{\circ} \mathrm{C} / \mathrm{min}$, then to $275^{\circ} \mathrm{C}$ at $7^{\circ} \mathrm{C} / \mathrm{min}$, followed by further increase to $320^{\circ} \mathrm{C}$ at $9^{\circ} \mathrm{C} / \mathrm{min}$. For USM, the initial temperature of the oven was set at $30^{\circ} \mathrm{C}$ for $1 \mathrm{~min}$, then programmed at a rate of $7^{\circ} \mathrm{C} / \mathrm{min}$ to $300^{\circ} \mathrm{C}$. MS was operated in the electron ionization mode at $70 \mathrm{eV}$ and the scan range was set at 40-600 m/z. Different constituents were identified based on comparing their relative retention times with those of authentic reference standards as well as matching their mass spectra with Replib, Manileb and Wiley library databases.

\subsubsection{Tocopherol Analysis of RSO}

HPLC analysis of tocopherols was performed, according to previously described method [23]. An HPLC system, Shimadzu Class-VP 5.03 (Kyoto, Japan), equipped with UV Shimadzu detector, LC-16 ADVP binary pump, DCou-14A degasser and Phenomenex Si $(250 \mathrm{~mm} \times 4.6 \mathrm{~mm}, 5 \mu \mathrm{m})$ column (Torrance, CA, USA) were used. Hexane/isopropanol $(99: 1, \mathrm{v} / \mathrm{v})$ was used as the mobile phase, at a flow rate of $0.65 \mathrm{~mL} / \mathrm{min}$. UV detection was set at $292 \mathrm{~nm}$ and the sample injection volume was $20 \mu \mathrm{L}$.

\subsection{Development of Nanoemulsion (RSO-NE)}

Aqueous titration method was used for the preparation of RSO-NE [24]. This was performed through vortexing of oil (final concentration: 7.5\% w/w) and Tween 80/PEG 400 (2:1) (final concentration: $55 \% \mathrm{w} / \mathrm{w}$ ), followed by stepwise addition of water (to complete the system weight to $100)$ to formulate a stable nanoemulsion. The nanoemulsion was kept at room temperature $\left(25^{\circ} \mathrm{C}\right)$ and observed for three months after formulation. The mean droplet size, polydispersity index (PDI) and zeta potential of the nanoemulsion were determined by photon correlation spectroscopy using a Zetasizer Nano ZS (Ver.6.20, Malvern Instruments Ltd., Worcestershire, England). The apparent pH of the nanoemulsion was measured by a pH meter (Mettler Toledo MP 220, Greifensee, Switzerland). All measurements were done, in triplicate, at room temperature $\left(25^{\circ} \mathrm{C}\right)$. The prepared formulation was diluted with acid buffer $\mathrm{pH} 1.2$ infinitely (i.e. 500 times). The diluted formulation was shaken and then visually inspected after 24 hours for any form of instability. Besides, the mean droplet size and polydispersity index (PDI) of the diluted formulation were measured. Finally, the morphology and 
structure of the nanoemulsion were visualized by transmission electron microscopy (TEM) (Jeol JEM 1230, Tokyo, Japan).

\subsection{Acute Toxicity Study}

Acute oral toxicity was performed for RSO-NE according to the OECD (Organization for Economic Cooperation and Development) guidelines.

\subsection{Hepatoprotective Activity}

\subsubsection{Experimental Animals}

Adult male Wistar albino rats (180-220 g), obtained from Helwan farm, Cairo, Egypt, were housed in the laboratory animal house of Faculty of Veterinary Medicine, Cairo University, Egypt. Animals were kept under standard laboratory conditions $\left(24 \pm 2^{\circ} \mathrm{C}\right.$ and $12 \mathrm{~h} \mathrm{light} / 12 \mathrm{~h}$ dark cycles $)$ with free access to commercial diet and water ad libitum, throughout the experimental period. Animals were allowed to acclimatize for one week to the current laboratory conditions, prior to starting the experiment. The experimental protocol was approved by Institutional Animal Care and Use Committee (IACUC), Cairo University, Egypt (Approval number of ethics committee, $\mathrm{CU} / \mathrm{III} / \mathrm{F} / 17 / 18)$.

\subsubsection{Experimental Design}

The in vivo hepatoprotective activity was assessed using paracetamol (PCM)-induced hepatoxicity model in rats [25]. The experiment lasted for six weeks where animals were pre-treated with the tested samples for five consecutive weeks; at the end of the fifth week liver intoxication was induced by single oral dose of PCM (2 g/kg, p.o.); treatments were administered for another week after liver damage. After acclimatization, a total of 56 rats were randomly allocated into 8 groups (7 rats/ group) as follows: (i) normal control group: rats received only the vehicle [0.5\% CMC (Carboxy methyl cellulose)], (ii) PCM group: rats received the vehicle and (2 g/ $\mathrm{kg}, \mathrm{PCM})$, (iii) silymarin group: rats were protected by silymarin $(100 \mathrm{mg} / \mathrm{kg}$ ), (iv) RSO-low dose group: rats were protected by RSO $(0.6 \mathrm{~mL} / \mathrm{kg})$, (v) RSO-medium dose group: rats were protected by RSO $(4 \mathrm{~mL} / \mathrm{kg}$ ), (vi) RSO-high dose group: rats were protected by RSO $(8 \mathrm{~mL} / \mathrm{kg}$ ), (vii) RSO-NE-low dose group: rats were protected by RSO-NE ( $4 \mathrm{~mL} / \mathrm{kg}$ ) and (viii) RSO-NE-medium dose group: rats were protected by RSO-NE (8 $\mathrm{mL} / \mathrm{kg}$ ). All treatments were suspended in $0.5 \%$ CMC and administered orally via gavage. PCM was administered orally after administration of the tested treatments to all groups except the normal control group. Twenty four hours after the last treatment dose, rats were anesthetized, blood samples were collected from the retro-orbital plexus and serum was separated by centrifugation and used for the assessment of liver markers. Animals were then sacrificed and liver tissues were isolated immediately, washed with ice cold saline $(0.9 \% \mathrm{NaCl})$, blotted dry. A portion of the liver was saved in $10 \%$ formalin for histopathological examination, while the remaining portions were stored at $-80^{\circ} \mathrm{C}$ for assessment of oxidative stress and inflammatory markers.

\subsubsection{Assessment of Liver Functional Markers}

Liver intoxication was assessed by determination of serum biomarkers such as alanine aminotransferase (ALT), aspartate aminotransferase (AST), alkaline phosphatase (ALP), gamma glutamyl transferase (GGT), total bilirubin (TB), total protein and albumin, using commercial assay kits (Biodiagnostic, Cairo, Egypt), according to manufacturer's protocol.

\subsubsection{Assessment of Oxidative Stress Markers}

Portion of livers was homogenized in ice-cold phosphate buffer saline (0.1 M PBS, pH 7.07.2). The homogenates were then centrifuged for $15 \mathrm{~min}$ at $4000 \mathrm{rpm}$ and the supernatants were 
collected for estimation of protein and oxidative stress markers. Protein content was determined using Bicinchoninic acid (BCA) protein assay kit (Biodiagnostic, Cairo, Egypt). Hepatic reduced glutathione (GSH) and hepatic malondialdehyde (MDA) levels were measured using commercial kits from (Biodiagnostic, Cairo, Egypt), while hepatic nuclear factor-erythroid 2-related factor2 (Nrf2) content was determined using commercial kits from (Mybiosource company, Southern California, San Diego, USA).

\subsubsection{Assessment of Inflammatory Markers}

Total RNA was extracted from liver tissue using a QIAamp RNeasy Mini kit (Qiagen, Germany), then eluted in $45 \mu \mathrm{L}$ of nuclease free distilled water and stored at $-20^{\circ} \mathrm{C}$ till analysis. Messenger RNA (mRNA) expression levels of tumor necrosis factor alpha (TNF- $\alpha$ ) and interleukin six (IL-6) were determined using the corresponding PCR fluorescence quantitative diagnostic kits (Cat.No. BSA09S2, SNP biotechnology R\&D, Turkey for TNF- $\alpha$ and Cat. No. BVI053S8, Qiagen, Valencia, CA for IL-6), which utilized sybegreen mastermix technology. Quantification was performed by Real time PCR device (Rotor-Gene Q5 plex real-time Rotary analyzer, Corbett Life Science, USA).

\subsubsection{Histopathological Analysis}

At the ending of the experimental period, specimens from liver of all animals were collected and fixed in $10 \%$ neutral buffered formalin, dehydrated in alcohol, cleared in xylene and embedded in paraffin. 4-5 $\mu \mathrm{m}$ Thick sections were prepared and stained with Hematoxylin and Eosin [26] for light microscope examination (Olympus BX50, Japan).

\subsubsection{Statistical Analyses}

Results were expressed as mean \pm S.D. and statistical comparisons were carried out using one way analysis of variance (ANOVA), followed by Tukey's Multiple Comparisons test. The minimal level of significance was identified at $\mathrm{P}<0.05$.

\section{Results and Discussion}

\subsection{Chemical Characterization of RSO}

Chemical characterization of RSO was performed as a prerequisite for its standardization and to explore the possible constituents associated with its mechanism of action.

Roselle seed yielded $17.5 \%$ oil, in accordance with previously reported data [14]. GC/MS analysis of the fatty acid composition revealed nineteen fatty acids, with unsaturated fatty acids representing $57.13 \%$ (Table 1$)$. Linoleic $(30.06 \%$, $\omega-6$ fatty acid) and oleic $(14.45 \%$, $\omega-9$ fatty acid) acids were the predominant unsaturated fatty acids, whereas palmitic and stearic acids (25.85 and $11.17 \%$, respectively) were the major saturated ones, in agreement with previous studies [13, 18, 27]. Total hydrocarbons constituted $88.83 \%$ of the unsaponifiable matter, while that of sterols represented $11.16 \%$ (Table 2). Sixteen hydrocarbons were identified, among which two long chain hydrocarbons (n-eicosane, $34.3 \%$ and $n$-nonadecane, $30.49 \%$ ) were the major components. On the other hand, four sterols were detected, with $\beta$-sitosterol (6.63\%) being the major one, followed by stigmasterol $(3.06 \%)$.

Furthermore, HPLC analysis revealed that RSO is a rich source of tocopherols (235.84 $\mathrm{mg} / 100 \mathrm{~g}$ oil, Table 3), 3-5 times higher than other vegetable oils such as sunflower, corn, rapeseed and soybean oils [28]. 
Table 1. Fatty acid profile of RSO

\begin{tabular}{|c|c|c|c|}
\hline & \\
\hline Fatty acids & $\begin{array}{c}\text { Relative } \\
\%\end{array}$ & Compound & $\begin{array}{c}\text { Relative } \\
\%\end{array}$ \\
\hline Myristic acid (C14:0) & 0.64 & $n$ - Heptane & 1.42 \\
\hline Pentadecanoic acid (C15:0) & 0.06 & $n$-Octane & 5.28 \\
\hline 7,10-Hexadecadienoic acid (C16:2) & 0.06 & $n$ - Nonane & 1.01 \\
\hline Palmitoleic acid (C16:1) & 2.50 & $n$ - Decane & 2.06 \\
\hline Palmitic acid (C16:0) & 25.85 & $n$-Undecane & 0.08 \\
\hline Civetic acid (C17:1) & 1.28 & $n$-Dodecane & 0.08 \\
\hline Margaric acid (C17:0) & 0.73 & $n$-Tridecane & 0.06 \\
\hline Linoleic acid (C18:2) & 30.06 & $n$-Tetradecane & 7.13 \\
\hline Oleic acid (C18:1) & 14.45 & $n$-Pentadecane & 3.48 \\
\hline Stearic acid (C18:0) & 11.17 & $n$ - Hexadecane & 0.13 \\
\hline 10-Nonadecenoic acid (C19:1) & 7.41 & $n$-Heptadecane & 0.93 \\
\hline$\gamma$-Linolenic acid (C18:3) & 0.35 & n-Octadecane & 0.26 \\
\hline$\alpha$-Linolenic acid (C18:3) & 0.64 & $n$ - Nonadecane & 30.49 \\
\hline Gondoic acid (C20:1) & 0.38 & $n$ - Eicosane & 34.30 \\
\hline Arachidic acid (C20:0) & 2.48 & $n$-Heneicosane & 2.01 \\
\hline Heneicosanoic acid (C21:0) & 0.07 & $n$-Docosane & 0.11 \\
\hline Behenic acid (C22:0) & 1.26 & Cholesterol & 0.18 \\
\hline Tricosylic acid (C23:0) & 0.12 & Campesterol & 1.29 \\
\hline Lignoceric acid (C24:0) & 0.48 & Stigmasterol & 3.06 \\
\hline Total saturated fatty acids & 42.86 & $\beta$-sitosterol & 6.63 \\
\hline \multirow[t]{2}{*}{ Total unsaturated fatty acids } & 57.13 & Total Hydrocarbons & 88.83 \\
\hline & & Total sterols & 11.16 \\
\hline
\end{tabular}

Tocopherols content is an important criterion in assessing seed oils, considering its inhibitory effect on lipid peroxidation of polyunsaturated fatty acids [29] which contributes to the oxidative stability of oil and hence enhance its quality and prolong its shelf life, in addition to their wellestablished health benefits [29]. The ratio of tocopherol isomers $(\alpha: \gamma: \delta)$ in roselle oil $(25: 64: 11)$ revealed the prevalence of $\gamma$-tocopherol (149.98 mg/100 g oil), being more than twice as much as its $\alpha$-tocopherol content $(58.7 \mathrm{mg} / 100 \mathrm{~g}$ oil), which is in agreement with previously reported data [15]. In contrast to $\alpha$-tocopherol, the $\gamma$-isomer revealed unique features and more significant contribution to human health, demonstrating more potent antioxidant and anti-inflammatory activities $[29,30]$.

Table 3. Tocopherol content of RSO

\begin{tabular}{lc}
\hline Tocopherol & Content $(\mathbf{m g} / \mathbf{1 0 0 g})$ \\
\hline$\alpha$-Tocopherol & 58.7 \\
$\gamma$-Tocopherol & 149.98 \\
$\delta$-Tocopherol & 27.16 \\
Total tocopherols & 235.84 \\
\hline
\end{tabular}

\subsection{Nanoemulsion Formulation of RSO}

RSO was successfully formulated as $\mathrm{O} / \mathrm{W}$ nanoemulsion to improve its aqueous solubility. The clear stable system consisted of 7.5\% oil (w/w) and 55\% (w/w) Tween 80/PEG 400 (2:1). The nanoemulsion was stable throughout the three months, where no signs of creaming, cracking or phase separation were noticed. The formulated nanoemulsion possessed a droplet size of $44.05 \pm 0.48 \mathrm{~nm}$, with a polydispersity index of $0.13 \pm 0.01$, indicating uniform size distribution (Figure S1). The zeta potential of the formula was $-16.40 \pm 0.42 \mathrm{mV}$ and the $\mathrm{pH}$ value was $5.38 \pm 0.14$. Upon dilution with acid buffer $\mathrm{pH} 1.2$, there were no significant changes in particle size $(46.72 \pm 0.89 \mathrm{~nm})$ and PDI 
$(0.21 \pm 0.06)$, which confirms the stability of the formulation under acidic $\mathrm{pH}$ conditions. TEM micrograph (Figure 1) revealed the droplets of nanoemulsion as discrete spherical globules, emerging as dark spots in a bright background, confirming the $\mathrm{O} / \mathrm{W}$ nature of the prepared nanoemulsion after dilution.

Pharmaceutical acceptability of all nanoemulsion ingredients for oral administration, regarding their safety, is the most essential criterion for selecting these ingredients. Besides, the solubilization capacity of the surfactant for the oil is a key point for formulating a stable nanoemulsion. $\mathrm{O} / \mathrm{W}$ nanoemulsions fabricated by nonionic surfactants are likely to be more stable in vivo [31], thus Tween80 (Hydrophilic lipophilic balance value=15) was chosen as surfactant and PEG 400 was selected as a cosurfactant to moderate the critical packing parameter of the used surfactant, which allow the ease of formulating richer water phases of $\mathrm{O} / \mathrm{W}$ nanoemulsions. In addition, the cosurfactant was perfectly inserted into the cavities between the surfactant molecules at the selected ratio of 2:1. Consequently, this resulted in enhancing the solubilization capacity of the nanoemulsion [24].

As per the physical stability, the formulation showed no signs of separation or creaming and its droplets appeared in TEM as distinct globules with no aggregations or signs of coalescence. Moreover, high negative zeta potential value verified the stability of nanoemulsion [20]. It is worth noting that the result of TEM was in a good agreement with that obtained from the Malvern particle size analyzer and PDI value below 0.2, designating a narrow size distribution, and thus ensured long-term stability of the nanoemulsion [32]. The measured $\mathrm{pH}$-values were found to be within the physiological range accepted for orally applied systems; $\mathrm{pH}=4.5-7$ [33], thus consenting the safety and the suitability of administering RSO-NE (containing 7.5\% RSO) through oral route.

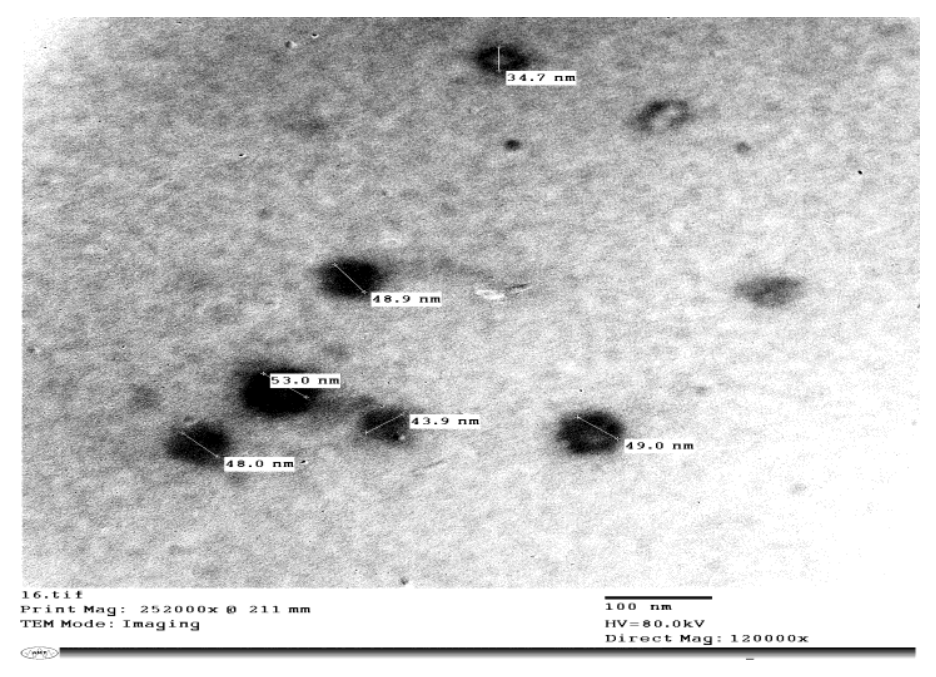

Figure 1. Transmission electron micrograph of RSO-NE

\subsection{Acute Toxicity Study}

Acute oral toxicity of RSO was previously examined [16] and was found to be safe up to 20 $\mathrm{mL} / \mathrm{kg}$, p.o. The investigated acute oral toxicity of RSO-NE herein did not exhibit any toxic symptoms, behavioral changes or mortality up to $120 \mathrm{~mL} / \mathrm{kg}$, p.o, indicating its safe use below this concentration. Therefore, oral doses of 4 and $8 \mathrm{~mL} / \mathrm{kg}$ were selected for the in vivo hepatoprotective study.

\subsection{Hepatoprotective Activity}

In this study, the hepatoprotective effects of RSO and its nanoemulsion (RSO-NE), at different dose levels, were demonstrated for the first time in PCM-induced hepatotoxic model. PCM-induced 
liver toxicity is a clinically applicable model, widely used to evaluate the hepatoprotective effectiveness of natural products and other constituents [34].

\subsubsection{RSO and Its Nanoemulsion Protected Liver Against PCM Intoxication}

The hepatoprotective activities of RSO and its nanoemulsion (RSO-NE) are summarized in Figure 2. Paracetamol-intoxicated rats showed significant liver damage, as evidenced by notable elevation in serum ALT, AST, ALP, GGT and total bilirubin as well as significant decrease in serum total protein and albumin, compared to normal control group $(\mathrm{p}<0.05)$. Pretreatment with RSO and RSO-NE significantly inhibited PCM-induced hepatotoxicity in a dose dependent manner $(\mathrm{p}<0.05)$, comparable to that of silymarin $(100 \mathrm{mg} / \mathrm{kg})$. RSO-NE at a dose of $8 \mathrm{~mL} / \mathrm{kg}$ revealed higher protective effect than unformulated seed oil at different tested doses, being equipotent or superior to silymarin $(100 \mathrm{mg} / \mathrm{kg})$.

\subsubsection{Histopathological Examination}

Microscopically, liver sections from normal control rats exhibited normal histological structure of hepatic lobule with normal central vein and concentrically arranged hepatocytes (Figure 3A). In contrast, PCM-intoxicated rats revealed severe cytoplasmic vacuolization of centrilobular hepatocytes, moderate pyknosis of hepatocytic nuclei, mild oedema in the portal triad, hydropic degeneration of hepatocytes, moderate congestion of hepatic sinusoids and mild focal hepatic haemorrhage, in addition to moderate fibroplasia in the portal triad around the bile duct (Figure 3B, 3C).

However, liver of rats pretreated with silymarin showed improved histopathological picture as most examined sections revealed changes confined as moderate Kupffer cells activation, mild binucleation of hepatocytes and mild cytoplasmic vacuolization of centrilobular hepatocytes (Figure 3D). Most examined sections from RSO group ( $0.6 \mathrm{~mL} / \mathrm{kg}$ b.wt.) revealed some histopathological changes as moderate Kupffer cells activation and binucleation of hepatocytes. Some examined sections showed mild focal hepatic necrosis associated with inflammatory cells infiltration and severe portal infiltration with inflammatory cells (Figure 3E). Liver of rats from RSO group ( $4 \mathrm{~mL} / \mathrm{kg} \mathrm{b.wt.)}$ showed moderate changes as Kupffer cells activation and focal hepatic necrosis associated with inflammatory cells infiltration. Mild fibroplasia in the portal triad was also observed in some sections (Figure 3F). Most examined sections from RSO group ( $8 \mathrm{~mL} / \mathrm{kg}$ b.wt.) revealed no histopathological changes, whereas few sections showed moderate Kupffer cells activation (Figure 3G) and mild sinusoidal leucocytosis. Moreover, most examined sections from rats in RSO-NE group $(4 \mathrm{~mL} / \mathrm{kg}$ b.wt.) revealed changes described as moderate cytoplasmic vacuolization of centrilobular hepatocytes (Figure $3 \mathrm{H}$ ), pyknosis of hepatocytic nuclei and mild Kupffer cells activation. Few sections from this group showed mild focal hepatic necrosis associated with inflammatory cell infiltration. Rats from RSO-NE group ( $8 \mathrm{~mL} / \mathrm{kg}$ b.wt.) revealed normal hepatic parenchyma with no histopathological alterations (Figure 3I), whereas some sections revealed mild changes as cytoplasmic vacuolization of centrilobular hepatocytes and Kupffer cell activation.

The hepatoprotective actions of RSO and RSO-NE were thus evidenced by maintaining adequate liver function despite of PCM administration. This was further confirmed by histopathological examination where RSO and RSO-NE maintained hepatocellular membrane integrity and the overall architecture of liver tissues. The efficacy of the oil was obviously enhanced via incorporation into nano-formulation.

PCM toxicity is initiated by the production of $\mathrm{N}$-acetyl $p$-benzoquinone imine (NAPQI), a reactive toxic metabolite, which depletes hepatic GSH and binds to hepatic cellular proteins, resulting in mitochondrial oxidative stress, peroxy nitrite formation and eventually mitochondrial dysfunction, DNA damage and liver injury [34]. 


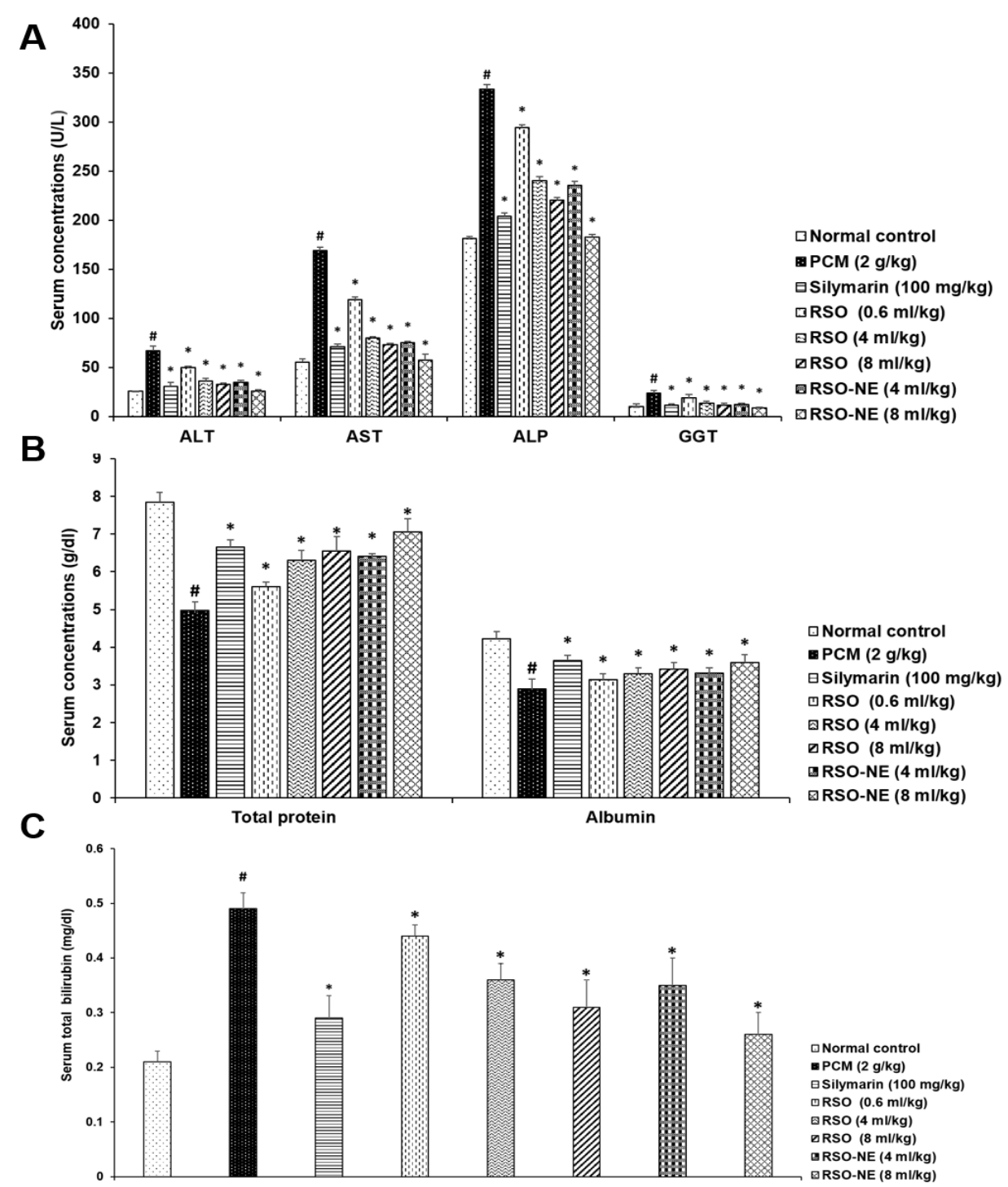

Figure 2. Effect of roselle oil (RSO) and its nanoemulsion (RSO-NE) on serum levels of ALT, AST, ALP, GGT (A), Total protein and albumin (B) and total bilirubin (C) in PCM-intoxicated rats. Data are expressed as mean $\pm \mathrm{SD}, \mathrm{n}=7$. $\# \mathrm{p}<0.05$ versus normal control group; $* \mathrm{p}<0.05$ versus PCM group.

Damaged hepatocytes subsequently activate hepatic macrophages via the release of damage associated molecular pattern molecules, resulting in significant increase in the expression of proinflammatory cytokines such as TNF- $\alpha$, IL- $1 \beta$ and IL-6, further contributing to liver-injury progression [35]. Consequently, PCM liver intoxication is mainly mediated by oxidative stress and inflammation. Therefore, the effect of RSO and RSO-NE on hepatic oxidative stress and inflammatory markers was investigated to explore their possible mechanistic action. 

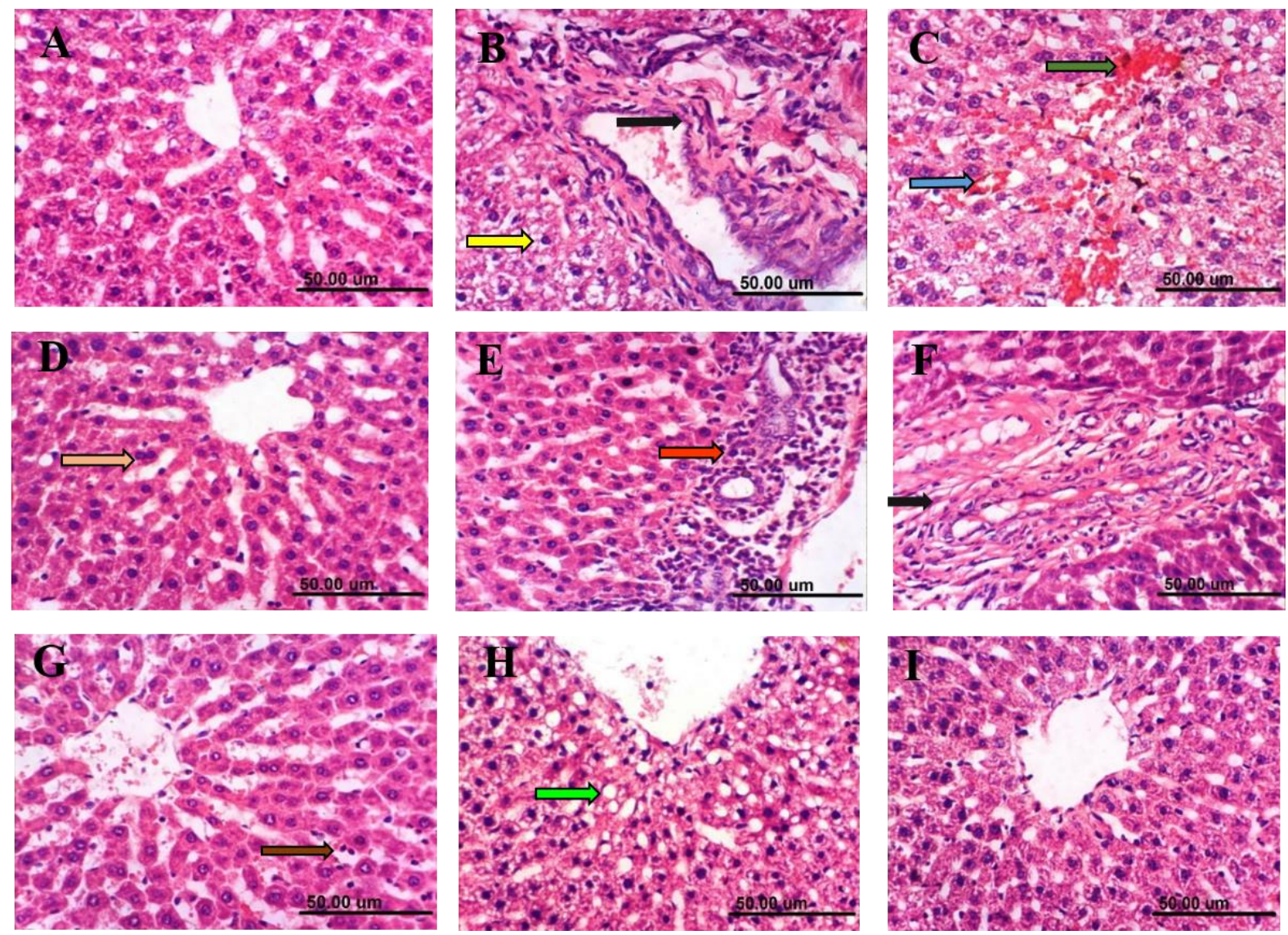

Figure 3. Effect of roselle oil (RSO) and its nanoemulsion (RSO-NE) on the liver histopathology of PCM-intoxicated rats. Photomicrographs of liver sections of normal control group (A), PCM-treated group (B\&C), silymarin (100 mg/kg)-treated group (D), RSO (0.6 mL/kg)-treated group (E), RSO (4 $\mathrm{mL} / \mathrm{kg}$ )-treated group $(\mathrm{F})$, RSO $(8 \mathrm{~mL} / \mathrm{kg})$-treated group $(\mathrm{G}), \mathrm{RSO}-\mathrm{NE}(4 \mathrm{~mL} / \mathrm{kg})$-treated group $(\mathrm{H})$, RSO-NE ( $8 \mathrm{~mL} / \mathrm{kg}$ )-treated group (I). Hydropic degeneration of hepatocytes (yellow arrow), fibroplasia in the portal triad (black arrow), congestion of hepatic sinusoids (blue arrow), focal hepatic haemorrhage (green arrow), binucleation of hepatocytes (orange arrow), portal infiltration with inflammatory cells (red arrow), Kupffer cells activation (brown arrow) and cytoplasmic vacuolization of centrilobular hepatocytes (light green arrow), (H \& E, scale bar $50 \mu \mathrm{m})$.

\subsubsection{RSO and its Nanoemulsion Attenuated Hepatic Oxidative Stress}

PCM administration induced oxidative stress as revealed by significant decrease in hepatic GSH levels and increase in MDA levels, compared to normal control group ( $p<0.05$, Figure 4$)$. However, RSO and RSO-NE pretreated groups dose-dependently reversed PCM-induced oxidative stress and were comparable to silymarin ( $\mathrm{p}<0.05$, Figure 4). Additionally, PCM resulted in significant decrease in hepatic levels of Nrf2, compared to normal control group ( $p<0.05$, Figure 4$)$, which was significantly attenuated by pretreatment with silymarin $(100 \mathrm{mg} / \mathrm{kg})$ or RSO and RSO-NE in a dose dependent manner. The nanoemulsion $(8 \mathrm{~mL} / \mathrm{kg})$ was the most effective treatment.

Oxidative stress has a key role in the progress of PCM-induced hepatotoxicity, in which GSH depletion represents one of the most essential mechanisms involved in its initial steps. Furthermore, the transcription factor, Nrf2 has shown a major defense role against PCM-induced hepatotoxicity through regulation of GSH synthesis and cellular detoxification processes [36]. Some compounds have demonstrated hepatoprotection in different oxidative stress models via activation of Nrf2 [37]. In the current study, the downregulation of hepatic Nrf2 and GSH with the subsequent increase in hepatic MDA, manifested in PCM group, were significantly ameliorated by RSO and RSO-NE pretreatments 
in a dose dependent manner. Thus, restoration of GSH normal levels upon pretreatment with RSO and RSO-NE could be attributed to two mechanisms factors. First, the inherent antioxidant activity of the oil components, thereby GSH is not much depleted by high levels of NAPQI. Second, the increased production of GSH via activation of its upstream transcription factor; Nrf-2. The inherent antioxidant activity was revealed in another unrelated model, where RSO exhibited strong radical scavenging and antioxidant activities in vitro, and significantly reduced lipid peroxidation in dyslipidemic rats [11].

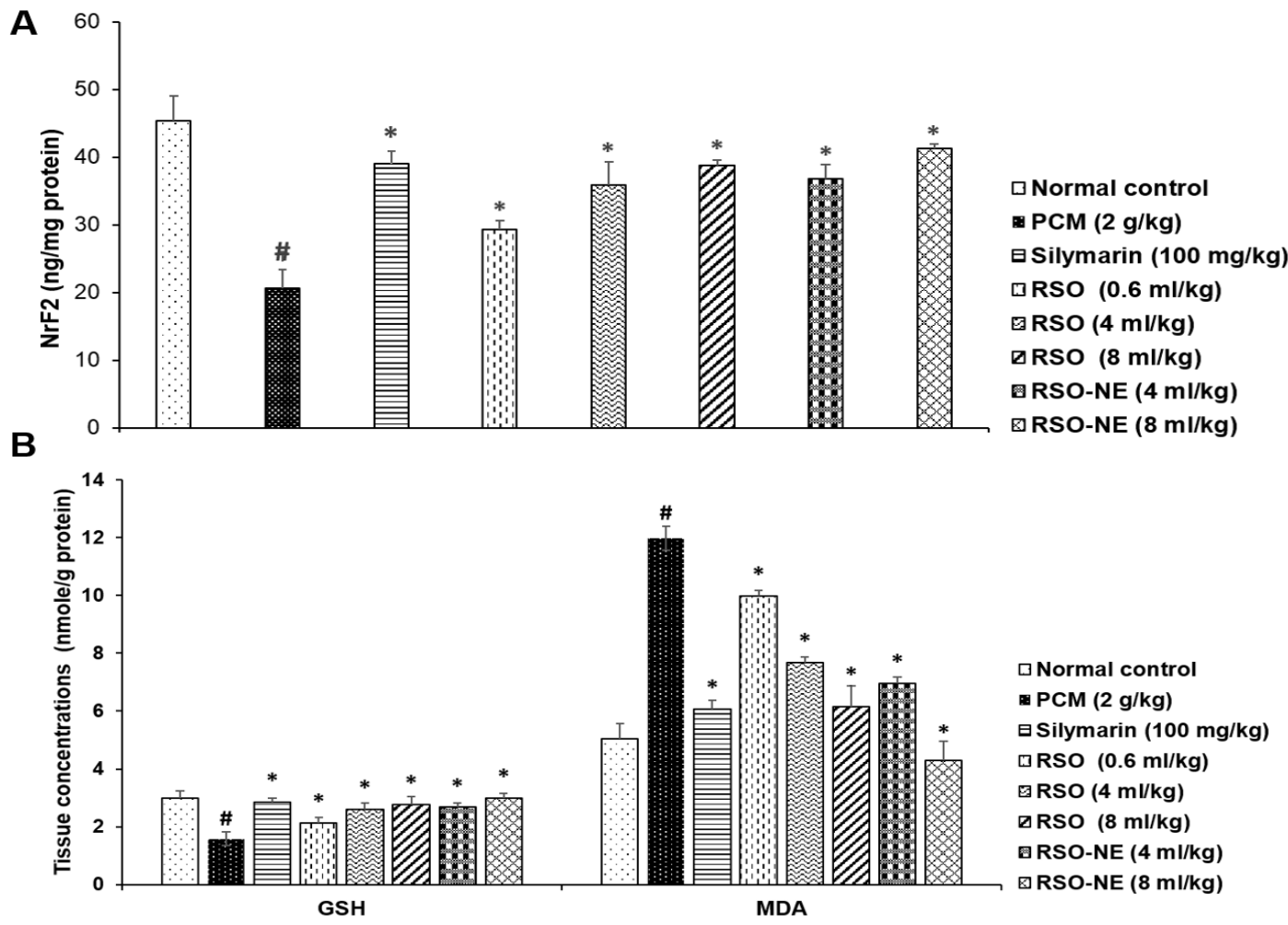

Figure 4. Effect of roselle oil (RSO) and its nanoemulsion (RSO) on the levels of Nrf2 (A), GSH and MDA (B) in livers of PCM-intoxicated rats. Data are expressed as mean $\pm S D, n=7$. $\# p<0.05$ versus normal control group; ${ }^{*} \mathrm{p}<0.05$ versus PCM group.

\subsubsection{RSO and Its Nanoemulsion Inhibited the Expressions of Pro-inflammatory Cytokines}

TNF- $\alpha$ plays an important role in mediating liver injury, triggering a cascade of proinflammatory mediators, including IL-6 [38]. Therefore, liver mRNA expressions of TNF- $\alpha$ and IL-6 were evaluated for the most effective doses $(8 \mathrm{~mL} / \mathrm{kg}$, each), regarding the previously investigated parameters. Hepatic mRNA expressions of TNF- $\alpha$ and IL- 6 were significantly up-regulated in PCMintoxicated rats, compared to normal control group ( $p<0.05$, Figure 5), suggesting induction of inflammatory response. RSO $(8 \mathrm{~mL} / \mathrm{kg})$, RSO-NE $(8 \mathrm{~mL} / \mathrm{kg})$ and silymarin $(100 \mathrm{mg} / \mathrm{kg})$ significantly inhibited mRNA expressions of these inflammatory mediators $(\mathrm{p}<0.05$, Figure 5$)$, suggesting that their hepatoprotective action is partly through suppressing hepatic inflammation. RSO-NE $(8 \mathrm{~mL} / \mathrm{kg})$ revealed to be more effective than $\mathrm{RSO}(8 \mathrm{~mL} / \mathrm{kg})$ and close or equipotent to silymarin. In agreement, RSO was reported to be a potent anti-inflammatory, comparable to diclofenac sodium and indomethacin, in different animal models [16,17], and its inhibitory effect on the pro-inflammatory cytokine, IL-6 was documented in dyslipedimic rats [11].

In this study, the hepatoprotective, antioxidant and anti-inflammatory effects of RSO and RSONE were comparable to that of silymarin. RSO $(8 \mathrm{~mL} / \mathrm{kg})$ exerted significant hepatoprotective effect, 
nearly close to that of silymarin, thus supporting the traditional use of the seeds in liver disorders. Furthermore, the formulated seed oil (RSO-NE, $8 \mathrm{~mL} / \mathrm{kg}$ ) revealed to be the most effective treatment, being equipotent or superior to silymarin $(100 \mathrm{mg} / \mathrm{kg})$. This demonstrated the enhanced efficacy of RSO upon incorporation into nano-drug delivery system.

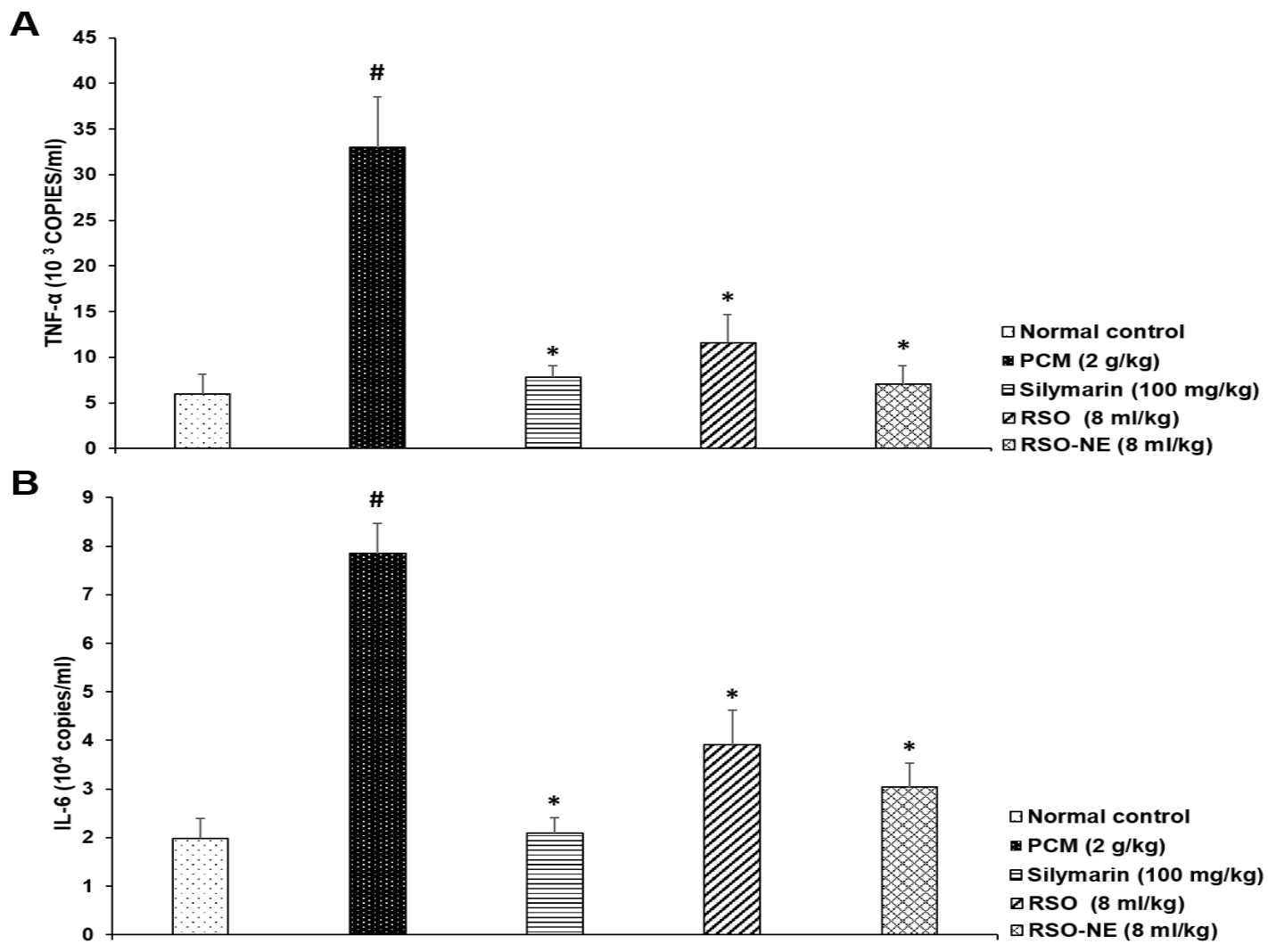

Figure 5. Effect of roselle oil (RSO) and its nanoemulsion (RSO-NE) on m-RNA expressions of TNF$\alpha$ (A) and IL-6 (B) in the livers of PCM-intoxicated rats. Data are expressed as mean \pm SD, $n=7$. $\# p<0.05$ versus normal control group; ${ }^{*} \mathrm{p}<0.05$ versus PCM group.

\subsection{Previous Reports on Biological Activities of RSO Constituents: Correlation to its Hepatoprotective Effect}

The significant hepatoprotective effect of RSO demonstrated herein can be attributed to its major components, namely fatty acids (linoleic, oleic, palmitic and stearic acids), tocopherols (especially $\gamma$-tocopherol), $\beta$-sitosterol and $n$-eicosane through their antioxidant and anti-inflammatory activities.

Linoleic acid, the major unsaturated fatty acid in RSO, is metabolized in the GIT into conjugated linoleic acid (CLA) [39]. Both have antioxidant and anti-inflammatory activities. CLA attenuated liver damage in $\mathrm{CCl}_{4}$-challenged rats by reducing lipid peroxidation, increasing hepatic reduced glutathione content as well as the activity of catalase and glutathione reductase [40]. According to [41], CLA enhanced the GSH/GSSG ratio, improved mitochondrial function, activated Nrf2 pathway in livers of high-fat diet rats and induced GSH synthesis in human fibroblasts [42]. In concurrence, it showed DPPH scavenging activity [43]. Nevertheless, the anti-inflammatory effects of linoleic acid and its metabolite (CLA) have been studied in various cell types [44-46]. Linoleic acid suppressed the expression of the pro-inflammatory cytokines; TNF- $\alpha$, IL- 6 and IL-1 $\beta$ through inhibition of NF- $\kappa \mathrm{B}$ in macrophages and human monocytic cells $[44,45]$.

Oleic acid acts similarly to linoleic acid. Oleic acid rich oils reduced plasma markers of liver damage (ALT, AST and ALP) in different animal models [47, 48]. In this aspect, olive oil alleviated 
acetaminophen-induced hepatotoxicity in mice through the antioxidant properties of its major components viz. oleic acid and tocopherols [48]. The antioxidative effect of oleic acid has been shown to be mediated via its ROS quenching activity [49], enhancement of ROS degradation [50] as well as protection against induced-structural damage of catalase and superoxide dismutase [51]. Its antiinflammatory effect has been associated with reducing pro-inflammatory cytokines (TNF- $\alpha$ and IL$1 \beta$ ) and elevating the levels of the anti-inflammatory cytokine; IL-10 during experimental sepsis [52].

Palmitic acid also can contribute in alleviation of hepatotoxicity by its antioxidant $[53,54]$ and anti-inflammatory activities [55-57]. It increased the expressions of HO-1 (heme oxygenase 1) and Nrf2 in HepG2 cells [54]. Furthermore, its inhibitory effect on the mRNA gene expression levels of TNF- $\alpha$ and IL-12 in human monocytic cells was reported [57], being mediated via NF- $\kappa B$ signaling pathway [55]. It has also shown to function as anti-inflammatory by inhibiting phospholipase $\mathrm{A}_{2}$ in an enzymatic kinetic study [56].

Supplementation of stearic acid, improved the recovery of hepatic dysfunction in different animal models $[58,59]$. It ameliorated hepatic biochemical markers (ALT, AST, GGT and albumin) in a cholestasis-induced liver injury model [58]. Hepatoprotection afforded by stearic acid was shown to be correlated to its anti-inflammatory potential [58]. It mitigated induced-liver inflammation via suppressing inflammatory cells accumulation and NF- $\mathrm{KB}$ activation. Additionally, it induced the production of the anti-inflammatory cytokine; IL-10 in rat hepatocytes [60]. Moreover, the antiinflammatory potential of stearic acid may be partly attributed to its antioxidant properties. It protected cortical neurons against oxidative stress via enhancing the activity of antioxidant enzymes [61]. Alike palmitic acid, stearic acid significantly elevated the expressions of genes and proteins of $\mathrm{HO}-1$ and Nrf2 in HepG2 cells [54].

The hepatoprotective effects of $\alpha$ - and $\gamma$-tocopherol isomers were previously demonstrated in tert-butyl hydroperoxide-induced hepatotoxicity in HepG2 cells [62]. This protective effect was further confirmed in different animal models $[63,64]$, being attributable to their antioxidant properties. $\alpha$-Tocopherol protected liver against oxidative damage through inhibiting lipid peroxidation, restoring hepatic activities of catalase and superoxide dismutase, and decreasing GSH content in liver [64]. The potent antioxidant properties of tocopherols can be attributed to their direct quenching activities of reactive nitrogen species [30]. In this aspect, $\gamma$-tocopherol was superior to its $\alpha$-isomer in trapping nitrogen dioxide and peroxynitrite, thus more effectively protecting against lipid peroxidation [30]. Additionally, a mixed tocopherol diet, enriched in $\gamma$-tocopherol, induced the expression of Nrf2 and phase II detoxifying enzymes in liver tissues [65]. The anti-inflammatory potential of tocopherols, specifically $\gamma$-tocopherol has been demonstrated in vitro as well as in animal and clinical models [30, 66]. $\gamma$-Tocopherol is shown to suppress COX and 5-LOX mediated biosynthesis of eicosanoids ( $\mathrm{PGE}_{2}$ and $\mathrm{LTB}_{4}$ ) in various cellular environments and animal models, more effectively than its $\alpha$-isomer [30]. It is worth noting that a combination of $\gamma$ - and $\alpha$-tocopherol suppressed inflammation and ameliorated oxidative stress in clinical studies [30].

The hepatoprotective effect of $\beta$-sitosterol in ethanol-induced rats was also reported, being associated with its antioxidant properties [67]. It inhibited lipid peroxidation and improved hepatic antioxidant status by enhancing enzymatic and non-enzymatic antioxidants [67]. In $\mathrm{CCl}_{4}$-challenged rats, $\beta$-sitosterol afforded hepatoprotection via enhancing the mitochondrial glutathione redox staus and improving the functional ability of mitochondria in rat livers [68]. Additionally, the potent free radical scavenging effect of $\beta$-sitosterol was demonstrated in different in vitro assays as well as in vivo [69]. Its anti-inflammatory activity was previously documented in different animal models [70-72]. The inhibitory effect of $\beta$-sitosterol on pro-inflammatory mediators such as IL-1 $\beta$, IL- 6 and TNF- $\alpha$ through NF- $\mathrm{kB}$ pathway was reported [70, 72]. It further increased the levels of IL-10 in macrophages [73] as well as in mice [72].

Nevertheless, a recent publication [57] reported the inhibitory effects of the hydrocarbons; eicosane and pentadecane on the genes expression of TNF- $\alpha$ and IL-12 in vitro.

\section{Conclusions}

RSO is a highly nutritious oil, rich in fatty acids, tocopherols, $\beta$-sitosterol and $n$-eicosane. For the first time, an optimized thermodynamically stable seed oil-loaded nanoemulsion formulation 
consisting of RSO, Tween 80/PEG 400 and water (7.5: 55: 37.5) was developed to improve the oral bioavailability of the oil and enhance its biological activity and stability. Besides, nanoemulsion system plays an important role in protecting active drug molecule from degradation in the stomach and at the same time prevents possible gastrointestinal tract irritation that may be caused by the drug. The major disadvantage of nanoemulsions is the cost of fabrication. The current study provides the first evidence for the hepatoprotective effect of RSO and its nanoemulsion formulation. Alleviation of oxidative stress, activation of $\mathrm{Nrf} 2$ and downregulation of m-RNA expression genes of proinflammatory cytokines might be possible mechanisms underlying the promising effect of this oil. Based on our findings, the major bioactive components of RSO may contribute synergistically to its protective effect through their antioxidant and anti-inflammatory activities. This study scientifically supports the ethnomedicinal use of roselle seeds and encourages the utilization of RSO in the development of health promoting products such as food supplements, functional food and nutraceuticals. However, further detailed investigations and clinical studies, based on these findings are warranted. Owing to the poor water solubility and low oral bioavailability of silymarin [74], a future study merits to be designed firstly, to examine the pharmacokinetic properties of possible combinations of RSO and silymarin, incorporated in a nano-emulsion drug delivery system. Secondly, the in vivo hepatoprotective activity of the optimum combination is to be evaluated, as a promising alternative for patients with liver disorders.

\section{Supporting Information}

Supporting information accompanies this paper on http://www.acgpubs.org/journal/records-ofnatural-products

\section{ORCID}

Mai E. Hussein: 0000-0002-8838-8147

Amira S. El Senousy: 0000-0003-3418-7320

Wessam H. Abd-Elsalam: 0000-0002-7802-7903

Kawkab A. Ahmed: 0000-0001-7376-7411

Hesham I. El-Askary: 0000-0001-7764-6588

Samar M. Mouneir: 0000-0001-6034-3177

Ahlam M. El Fishawy: 0000-0003-4925-7395

\section{References}

[1] D. K. Ingawale, S. K. Mandlik and S. R. Naik (2014). Models of hepatotoxicity and the underlying cellular, biochemical and immunological mechanism(s): A critical discussion, Environ. Toxicol. Pharmacol. 37, 118-133.

[2] I. A. Rowe (2017). Lessons from epidemiology: The burden of liver disease, Dig. Dis. 35, 304-309.

[3] N. Ghosh, R. Ghosh, V. Mandal and S. C. Mandal (2011). Recent advances in herbal medicine for treatment of liver diseases, Pharm. Biol. 49, 970-988.

[4] J. Rane, R. Jadhao and R. L. Bakal (2016). Liver diseases and herbal drugs: -A review, J. Innov. Pharm. Biol. Sci. 3, 24-36.

[5] P. Singh, M. Khan and H. Hailemariam (2017). Nutritional and health importance of Hibiscus sabdariffa: a review and indication for research needs, J. Nutr. Heal. Food Eng. 6, 125-128.

[6] I. Da-Costa-Rocha, B. Bonnlaender, H. Sievers, I. Pischel and M. Heinrich (2014). Hibiscus sabdariffa L. - a phytochemical and pharmacological review, Food Chem. 165, 424-443.

[7] J. K. Abat, S. Kumar and A. Mohanty (2017). Ethnomedicinal, phytochemical and ethnopharmacological aspects of four medicinal plants of Malvaceae used in Indian traditional medicines: A review, Medicines 4,75 .

[8] C. A. Lans (2006). Ethnomedicines used in Trinidad and Tobago for urinary problems and diabetes mellitus, J. Ethno. Bio.Med. 2, 1-11.

[9] A. Ismail, E. Hainida, K. Ikram, H. Saadiah and M. Nazri (2008). Roselle (Hibiscus sabdariffa L.) seeds - nutritional composition, protein quality and health benefits, Food 2, 1-16.

[10] K. L. Nyam, S. Y. Leao, C. P. Tan and K. Long (2014). Functional properties of roselle (Hibiscus sabdariffa L.) seed and its application as bakery product, J. Food Sci. Technol. 51, 3830-3837.

[11] S. Y. Al-Okbi, A. G. Abdel-Razek, S. E. Mohammed and M. E. S. Ottai (2017). Roselle seed as a 
potential new source of healthy edible oil, J. Biol. Sci. 17, 267-277.

[12] R. Mohamed, J. Fernández, M. Pineda and M. Aguilar (2007). Roselle (Hibiscus sabdariffa) seed oil is a rich source of $\gamma$-tocopherol, J. Food Sci. 72, S207-S212.

[13] K. L. Nyam, C. P. Tan, O. M. Lai, K. Long and Y. B. Che Man (2009). Physicochemical properties and bioactive compounds of selected seed oils, LWT - Food Sci. Technol. 42, 1396-1403.

[14] M. L. Wang, B. Morris, B. Tonnis, J. Davis and G. A. Pederson (2012). Assessment of oil content and fatty acid composition variability in two economically important Hibiscus species, J. Agric. Food Chem. 60, 6620-6626.

[15] S. M. El-deab and H. E. Ghamry (2017). Nutritional evaluation of roselle seeds oil and production of mayonnaise, Inter. J. Food Sci. Nutr. Engin.7, 32-37.

[16] S. K. Ali, A. H. Mohamed and G. E. Mohammed (2014). Fatty acid composition , anti-inflammatory and analgesic activities of Hibiscus sabdariffa Linn . seeds, J. Adv. Vet. Anim. Res. 1, 50-57.

[17] K. L. Nyam, L. N. Sin and L. Kamariah (2015). Phytochemical analysis and anti-inflammatory effect of kenaf and roselle seeds, Malays. J. Nutr. 21, 245-254.

[18] R. F. M. Ali and A. M. El-Anany (2017). Hypolipidemic and hypocholesterolemic effect of roselle (Hibiscus sabdariffa L.) seeds oil in experimental male rats, J. Oleo Sci. 66, 41-49.

[19] Z. P. Gumus, E. Guler, B. Demir, F. B. Barlas, M. Yavuz, D. Colpankan, A. M. Senisik, S. Teksoz, P. Unak, H. Coskunol and S. Timur (2015). Herbal infusions of black seed and wheat germ oil: Their chemical profiles, in vitro bio-investigations and effective formulations as phyto-nanoemulsions, Colloids Surf. B Biointerfaces 133, 73-80.

[20] G. Ragavan, Y. Muralidaran, B. Sridharan, R. Nachiappa Ganesh and P. Viswanathan (2017). Evaluation of garlic oil in nano-emulsified form: Optimization and its efficacy in high-fat diet induced dyslipidemia in Wistar rats, Food Chem.Toxicol. 105, 203-213.

[21] Y. Singh, J. G. Meher, K. Raval, F. A. Khan, M. Chaurasia, N. K. Jain and M. K. Chourasia (2017). Nanoemulsion: Concepts, development and applications in drug delivery, J. Control. Release 252, 2849.

[22] A. I. Vogel (1975). A text book of practical organic chemistry. Longmans and Green Co. Ltd., London.

[23] D. G. Stevenson, F. J. Eller, L. Wang, J. L. Jane, T. Wang and G. E. Inglett (2007). Oil and tocopherol content and composition of pumpkin seed oil in 12 cultivars, J. Agric. Food Chem. 55, 4005-4013.

[24] S. A. Tayel, M. A. El-Nabarawi, M. I. Tadros and W. H. Abd-Elsalam (2013). Promising ion-sensitive in situ ocular nanoemulsion gels of terbinafine hydrochloride: Design, in vitro characterization and in vivo estimation of the ocular irritation and drug pharmacokinetics in the aqueous humor of rabbits, Int. J. Pharm. 443, 293-305.

[25] G. Mishra, R. Khosa, P. Singh and K. Jha (2015). Hepatoprotective potential of ethanolic extract of Pandanus odoratissimus root against paracetamol-induced hepatotoxicity in rats, J. Pharm. Bioallied Sci. 7, 45-48.

[26] J. D. Bancroft and M. Gamble (2008). Theory and practice of histological techniques. Elsevier Health Sciences, China.

[27] H. O. Adubiaro, A. Olaleye and M. O. Oguntokun (2018). Characetrization of fatty acids of seasame, roselle and smooth loofah seeds, J. Bio Innov. 7, 310-319.

[28] A. Gliszczyńska-świgło, E. Sikorska, I. Khmelinskii and M. Sikorski (2007). Tocopherol content in edible plant oils, Polish J. Food Nutr. Sci. 57, 157-161

[29] K. Saldeen and T. Saldeen (2005). Importance of tocopherols beyond $\alpha$-tocopherol: Evidence from animal and human studies, Nutr. Res. 25, 877-889.

[30] Q. Jiang (2014). Natural forms of vitamin E: metabolism, antioxidant, and anti-inflammatory activities and their role in disease prevention and therapy, Free Radic. Biol. Med. 72, 76-90.

[31] A. Azeem, M. Rizwan, F. J. Ahmad, Z. Iqbal, R. K. Khar, M. Aqil and S. Talegaonkar (2009). Nanoemulsion components screening and selection: a technical note, AaPS PharmSciTech. 10, 69-76.

[32] V. Klang, N. B. Matsko, C. Valenta and F. Hofer (2012). Electron microscopy of nanoemulsions: An essential tool for characterisation and stability assessment, Micron 43, 85-103.

[33] D. S. Jones (2016). FASTtrack Pharmaceutics dosage form and design. Pharmaceutical Press, United Kingdom.

[34] H. Jaeschke, M. R. McGill, C. D. Williams and A. Ramachandran (2011). Current issues with acetaminophen hepatotoxicity - A clinically relevant model to test the efficacy of natural products, Life Sci. 88, 737-745.

[35] B. V. Martin-Murphy, M. P. Holt and C. Ju (2010). The role of damage associated molecular pattern molecules in acetaminophen-induced liver injury in mice, Toxicol. Lett. 192, 387-394.

[36] K. Chan, X. D. Han and Y. W. Kan (2001). An important function of Nrf2 in combating oxidative stress: detoxification of acetaminophen, Proc. Natl. Acad. Sci.U.S.A. 98, 4611-4616. 
[37] S. Li, H.-Y. Tan, N. Wang, Z.-J. Zhang, L. Lao, C.-W. Wong and Y. Feng (2015). The role of oxidative stress and antioxidants in liver diseases, Int. J. Mol. Sci. 16, 26087-26124.

[38] A. Chastre, M. Bélanger, E. Beauchesne, B. N. Nguyen, P. Desjardins and R. F. Butterworth (2012). Inflammatory cascades driven by tumor necrosis factor-alpha play a major role in the progression of acute liver failure and its neurological complications, PLoS One 7, 1-9.

[39] E. Devillard, F. M. McIntosh, S. H. Duncan and R. J. Wallace (2007). Metabolism of linoleic acid by human gut bacteria: Different routes for biosynthesis of conjugated linoleic acid, J. Bacteriol. 189, 2566-2570.

[40] E. B. T. De Carvalho, I. L. P. De Melo, A. M. D. Silva, D. A. P. Mancini and J. Mancini-filho (2014). Effect of conjugated linoleic acid (CLA) in rats subjected to damage liver induced by carbon tetrachloride, J. Mod. Med. Chem. 2, 32-42.

[41] M. P. Mollica, G. Trinchese, G. Cavaliere, C. De Filippo, E. Cocca, M. Gaita, A. Della-gatta, A. Marano, G. Mazzarella and P. Bergamo (2014). c9, t11-Conjugated linoleic acid ameliorates steatosis by modulating mitochondrial uncoupling and Nrf2 pathway, J. Lip. Res. 55, 837-849.

[42] K. Arab, A. Rossary, L. Souleère and J.-P. Steghens (2006). Conjugated linoleic acid, unlike other unsaturated fatty acids, strongly induces glutathione synthesis without any lipoperoxidation, Br. J. Nutr. 96, 811-819.

[43] N. Fagali and A. Catalá (2008). Antioxidant activity of conjugated linoleic acid isomers, linoleic acid and its methyl ester determined by photoemission and DPPH techniques, Biophys. Chem. 137, 56-62.

[44] G. Zhao, T. D. Etherton, K. R. Martin, J. P. Vanden Heuvel, P. J. Gillies, S. G. West and P. M. KrisEtherton (2005). Anti-inflammatory effects of polyunsaturated fatty acids in THP-1 cells, Biochem. Biophys. Res. Commun. 336, 909-917.

[45] P. Saiki, Y. Kawano, L. J. L. D. Van Griensven and K. Miyazaki (2017). The anti-inflammatory effect of Agaricus brasiliensis is partly due to its linoleic acid content, Food Funct. 8, 4150-4158.

[46] D. Dipasquale, L. Basiricò, P. Morera, R. Primi, A. Tröscher and U. Bernabucci (2018). Antiinflammatory effects of conjugated linoleic acid isomers and essential fatty acids in bovine mammary epithelial cells, Animal 12, 2108-2114.

[47] H. Poudyal, S. A. Kumar, A. Iyer, J. Waanders, L. C. Ward and L. Brown (2013). Responses to oleic, linoleic and $\alpha$-linolenic acids in high-carbohydrate, high-fat diet-induced metabolic syndrome in rats, $J$. Nutr. Biochem. 24, 1381-1392.

[48] M. A. B. Ibrahim, F. A. Wani and S. Rahiman (2017). Hepatoprotective effect of olive oil and camel milk on acetaminophen-induced liver toxicity in mice, Int. J. Med. Sci. Public Health 6, 186-194.

[49] M. Massaro, G. Basta, G. Lazzerini, M. A. Carluccio, F. Bosetti, G. Solaini, F. Visioli, A. Paolicchi and R. De Caterina (2002). Quenching of intracellular ROS generation as a mechanism for oleate-induced reduction of endothelial activation and early atherogenesis, Thromb. Haemost. 88, 335-344.

[50] C. Duval, N. Auge, M.-F. Frisach, L. Casteilla, R. Salvayre and A. Negre-Salvayre (2002). Mitochondrial oxidative stress is modulated by oleic acid via an epidermal growth factor receptordependent activation of glutathione peroxidase, Biochem. J. 367, 889-894.

[51] H. Mirmiranpour, S. Rabizadeh, M. A. Mansournia, S. S. Salehi, A. Esteghamati and M. Nakhjavani (2018). Protective effect of palmitoleic, oleic, and vaccenic acid on structure-function of major antioxidant enzymes: catalase, superoxide dismutase and glutathione peroxidase in the hyperglycemic environment: an in vitro study, Austin Biochem. 3, 1017.

[52] I. M. Medeiros-de-Moraes, C. F. Gonçalves-de-Albuquerque, A. R. M. Kurz, F. M. J. Oliveira, V. H. P. de Abreu, R. C. Torres, V. F. Carvalho, V. Estato, P. T. Bozza, M. Sperandio, H. C. de Castro-FariaNeto and A. R. Silva (2018). Omega-9 oleic acid, the main compound of olive oil, mitigates inflammation during experimental sepsis, Oxid. Med. Cell Longev. 2018, 1-13.

[53] G. E. Henry, R. A. Momin, M. G. Nair and D. L. Dewitt (2002). Antioxidant and cyclooxygenase activities of fatty acids found in food, J. Agric. Food Chem. 50, 2231-2234.

[54] H. Li-hong, Z. Xiu-ying, Z. Jin-ming, C. Xiao-xu, S. Xiao-qi and G. Shu-han (2016). Effects of palmitic acid and stearic acid on genes and protein expressions of heme oxygenase 1 and nuclear transcription factor Nrf2 in HepG2 cell, Acta Veterinar. Et Zootech. Sin. 47, 603-608.

[55] F. Debierre-Grockiego, K. Rabi, J. Schmidt, H. Geyer, R. Geyer and R. T. Schwarz (2007). Fatty acids isolated from Toxoplasma gondii reduce glycosylphosphatidylinositol-induced tumor necrosis factor alpha production through inhibition of the NF- kB signaling pathway, Infect. Immun. 75, 2886-2893.

[56] V. Aparna, K. V. Dileep, P. K. Mandal, P. Karthe, C. Sadasivan and M. Haridas (2012). Antiinflammatory property of $n$-Hexadecanoic acid: Structural evidence and kinetic assessment, Chem. Biol. Drug Des. 80, 434-439.

[57] X. Chuah, P. Okechukwu, F. Amini and S. Teo (2018). Eicosane, pentadecane and palmitic acid: The effects in in vitro wound healing studies, Asian Pac. J. Trop. Biomed. 8, 490-499.

[58] P.-H. Pan, S.-Y. Lin, Y.-C. Ou, W.-Y. Chen, Y.-H. Chuang, Y.-J. Yen, S.-L. Liao, S.-L. Raung and C.-J. 
Chen (2010). Stearic acid attenuates cholestasis-induced liver injury, Biochem. Biophys. Res. Commun. 391, 1537-1542.

[59] N. H. Goradel, M. A. Eghbal, M. Darabi, L. Roshangar, M. Asadi, N. Zarghami and M. Nouri (2016). Improvement of liver cell therapy in rats by dietary stearic acid, Iran Biomed. J. 20, 217-222.

[60] Y. Nishitani, S. Okazaki, K. Imabayashi, R. Katada, K. Umetani, H. Yajima and H. Matsumoto (2007). Saturated and monounsaturated fatty acids increase interleukin-10 production in rat hepatocytes, Nihon Aruk.Yakubut. Igakk. Zasshi 42, 32-35.

[61] Z.-J. Wang, C.-L. Liang, G.-M. Li, C.-Y. Yu and M. Yin (2007). Stearic acid protects primary cultured cortical neurons against oxidative stress, Acta Pharmacol. Sin. 28, 315-326.

[62] K. H. Seo, D. Y. Lee, D. S. Lee, H. C. Kang, H. S. Kim, Y. C. Kim and N. I. Baek (2015). Hepatoprotective and neuroprotective tocopherol analogues isolated from the peels of Citrus unshiu Marcovich, Nat. Prod. Res. 29, 571-573.

[63] V. Tayal, B. S. Kalra, S. Agarwal, N. Khurana and U. Gupta (2007). Hepatoprotective effect of tocopherol against isoniazid and rifampicin induced hepatotoxicity in albino rabbits, Indian J. Exp. Biol. 45, 1031-1036.

[64] H. Chalouati, M. M. Ben Sâad and L. Payrastre (2019). Hepatoprotective effects of vitamin E against hexachlorobenzene-induced hepatotoxicity and oxidative stress in rats: histological, biochimical and antioxidant status changes, Toxicol. Mech. Methods 29, 18-25.

[65] A. K. Smolarek, J. Y. So, P. E. Thomas, H. J. Lee, S. Paul, A. Dombrowski, C. X. Wang, C. L. L. Saw, T. O. Khor, A. N. T. Kong, K. Reuhl, M. J. Lee, C. S. Yang and N. Suh (2013). Dietary tocopherols inhibit cell proliferation, regulate expression of $\operatorname{ER} \alpha, \operatorname{PPAR} \gamma$, and $\mathrm{Nrf} 2$, and decrease serum inflammatory markers during the development of mammary hyperplasia, Mol. Carcinog. 52, 514-525.

[66] E. Reiter, Q. Jiang and S. Christen (2007). Anti-inflammatory properties of $\alpha$ - and $\gamma$-tocopherol, Mol. Aspects Med. 28, 668-691.

[67] S. M. R. Sujila, M. Rajadurai and S. M. R. Shairibha (2014). Hepatoprotective effect of $\beta$-sitosterol on lipid peroxidation and antioxidant status in ethanol-induced hepatotoxic rats, Int. J. Integr. Sci. Innov. Technol. 3, 1-11.

[68] H. S. Wong, J. H. Chen, P. K. Leong, H. Y. Leung, W. M. Chan and K. M. Ko (2014). $\beta$-Sitosterol protects against carbon tetrachloride hepatotoxicity but not gentamicin nephrotoxicity in rats via the induction of mitochondrial glutathione redox cycling, Molecules 19, 17649-17662.

[69] M. Ayaz, M. Junaid, F. Ullah, F. Subhan, A. Sadiq, G. Ali, M. Ovais, M. Shahid, A. Ahmad, A. Wadood, M. El-Shazly, N. Ahmad and S. Ahmad (2017). Anti-Alzheimer's studies on $\beta$-sitosterol isolated from Polygonum hydropiper L ., Front Pharmacol. 8, 697.

[70] K.-A. Kim, I.-A. Lee, W. Gu, S. R. Hyam and D.-H. Kim (2014). ß-Sitosterol attenuates high-fat dietinduced intestinal inflammation in mice by inhibiting the binding of lipopolysaccharide to toll-like receptor 4 in the NF- kB pathway, Mol. Nutr. Food Res. 58, 963-972.

[71] R. Paniagua-Pérez, G. Flores-Mondragón, C. Reyes-Legorreta, B. Herrera-López, I. CervantesHernández, O. Madrigal-Santillán, J. A. Morales-González, I. Álvarez-González and E. MadrigalBujaidar (2017). Evaluation of the anti-inflammatory capacity of Beta-sitosterol in rodent assays, African J. Tradit. Complement. Altern. Med. 14, 123-130.

[72] R. Liu, D. Hao, W. Xu, J. Li, X. Li, D. Shen, K. Sheng, L. Zhao, W. Xu, Z. Gao, X. Zhao, Q. Liu and Y. Zhang (2019). $\beta$-Sitosterol modulates macrophage polarization and attenuates rheumatoid inflammation in mice, Pharm Biol. 57, 161-168.

[73] M. Valerio and A. B. Awad (2011). $\beta$-Sitosterol down-regulates some pro-inflammatory signal transduction pathways by increasing the activity of tyrosine phosphatase SHP-1 in J774A.1 murine macrophages, Int. Immunopharmacol. 11, 1012-1017.

[74] S. Javed, K. Kohli and M. Ali (2011). Reassessing bioavailability of silymarin, Altern. Med. Rev. 16, 239-249.

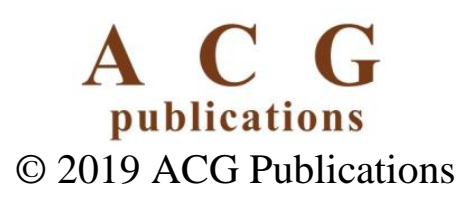

